Article

\title{
Sustainable and Affordable Prefabricated Construction: Developing a Natural, Recycled, and Recyclable Mobile Home
}

\author{
Carlo Berizzi $^{1, *(\mathbb{D}}$, Salvatore Nirta ${ }^{1}\left(\mathbb{D}\right.$, Gaia Nerea Terlicher ${ }^{1, *(\mathbb{D})}$ and Luca Trabattoni ${ }^{2}(\mathbb{D}$ \\ 1 Department of Civil Engineering and Architecture, University of Pavia, 27100 Pavia, Italy; \\ salvatore.nirta@gmail.com \\ 2 Department of Architecture and Urban Planning, Opole University of Technology, 45-758 Opole, Poland; \\ 1.trabattoni@po.edu.pl \\ * Correspondence: carlo.berizzi@unipv.it (C.B.); gaianerea.terlicher01@universitadipavia.it (G.N.T.)
}

Citation: Berizzi, C.; Nirta, S.;

Terlicher, G.N.; Trabattoni, L.

Sustainable and Affordable

Prefabricated Construction:

Developing a Natural, Recycled, and

Recyclable Mobile Home.

Sustainability 2021, 13, 8296.

https://doi.org/10.3390/su13158296

Academic Editor: Antonio Caggiano

Received: 17 June 2021

Accepted: 19 July 2021

Published: 25 July 2021

Publisher's Note: MDPI stays neutral with regard to jurisdictional claims in published maps and institutional affiliations.

Copyright: (c) 2021 by the authors. Licensee MDPI, Basel, Switzerland. This article is an open access article distributed under the terms and conditions of the Creative Commons Attribution (CC BY) license (https:// creativecommons.org/licenses/by/ $4.0 /)$

\begin{abstract}
Outdoor tourism is a form of outdoor holiday that is growing rapidly today, and that stands out from other forms of tourism for its immediate relationship with the landscape which becomes for the tourist the main attraction of the holiday intended as a break from ordinary urban life. Outdoor tourism today represents a growing percentage in the tourism sector, in which mobile homes are the real players. Despite the considerable use of this product in open-air accommodations located in relevant landscapes, there is still no sensitivity in the constructive approach and in the choice of materials in terms of sustainability. In the open-air tourism sector, the lack of ecological sensitivity results from two levels of application: one regarding the whole settlement and the public spaces of outdoor accommodations and one regarding the mobile unit from the design to the production process. This paper will provide some practical strategies to introduce the ecological theme in the mobile home for the tourism sector. The research aims to analyze the production system of mobile homes in order to introduce alternative materials within the existing assembly line. The research demonstrates the possibility of a product being sustainable both economically and environmentally, healthy, and well-integrated with landscape by adopting an approach that makes it possible to use the same assembly line currently in use.
\end{abstract}

Keywords: sustainability; outdoor tourism; mobile home; ecology; prototype

\section{Introduction}

The global impact of the entire construction sector today is estimated at around 30\% [1]. This impact is due not only to the energy and consumption cost of $\mathrm{CO}_{2}$ related to handling and transportation, but also to the enormous consumption of material, often not renewable. Furthermore, the construction industry is responsible for over $30 \%$ of global greenhouse gas emissions (GHGE) and 36\% of global waste production that can be quantified as 3.8 billion per year [1].

It is not only the construction system that includes building is responsible for negatively affecting the environment, but also the process of demolition which generates waste that cannot be reused. Nevertheless, the most used materials in construction are cement and concrete, which in terms of carbon dioxide emissions and depletion of fossil energy resources represent the worst materials [2].

It is obvious today that the building sector is the cause of a high percentage of GHGE in the world; thus by working in a more conscious way, it can play an important role in sustainable development. The sector can contribute promoting sustainable architecture, which means using materials that are environmentally friendly, in which the purpose of architecture is to reduce irreversible impacts on the environment and human health [3].

According to the International Resource Panel, by using "material efficiency strategies", such as the use of alternative and recycling materials, it will be possible to reduce emissions from material cycle of residential buildings in the G7 states by $80 \%$ in 2050 
(United Nations Environment Programme (UNEP) 2019) [4]. Even the 2019 Global Status Report for Buildings and Construction promotes the reduction of demolition and the development of a circular economy in the building sector in order to reduce emissions that have increased from 2017 to 2018 [5].

The use of alternative materials, such as natural, recycled, and recyclable materials, represents the new frontier for the building sector to contribute significantly to sustainability. Using recycled and recyclable materials means selecting them according to their life cycle, preventing the exploitation of resources and reducing the production of waste generating a "closed circulation of components" [3]. Recycling and reusing strategies can avoid producing more energy for new buildings' construction by earning energy from existing building materials [6]. In this way, waste material becomes a resource contributing to a good circular economy practice in which the concept is to work on the building sector such as nature does: using natural materials and recycling materials in a cyclic optic that does not know the meaning of waste [7]. The conscious use of materials in construction is also one of the prerogatives of the 2030 Agenda for Sustainable Development which aims to make human settlements sustainable by guaranteeing sustainable production and consumption models, trying to protect and promote sustainable use of the terrestrial ecosystem.

Using sustainable materials means using resources consciously, and positively affecting, as the report "Our Common Future" states, the world's balance by providing natural environmental, economic, and social benefits [8].

Natural, recycled, and recyclable materials can all be considered eco-friendly even if they are of different origin and nature: naturals derive directly from raw materials which of course do not cause $\mathrm{CO}_{2}$ emissions and add to air pollution, consequently creating a healthy environment for humans; recycled materials derive from waste materials reducing them and can be natural or artificial; recyclable materials provide an opportunity for the future and can include natural or artificial materials that can be reused again in another process.

One of the most spectacular forms of the present is tourism, which is a mirror of contemporary society [9]. Sustainability in the field of tourism finds an immediate comparison with outdoor tourism where there is a strong relationship with nature and the surrounding landscape. However, the reflection on sustainability in this field needs to be analyzed on different levels including taking into account the sustainability value of the individual accommodation unit. The placement of accommodation facilities in particularly sensitive areas of the territory and of particular landscape interest requires greater sensitivity to sustainability issues both in terms of composition at an architectural level and in a technical key through the use of properly selected materials with respect to the environment. Thus, the need for improvement on a sustainable level does not only concern ordinary buildings today. The theme of outdoor tourism still has deep gaps and it needs more sensitivity in terms of ecology. In Italy alone, there are more than 2600 outdoor accommodations and that can accommodate together up to 1,000,000 tourists at the same time, considering that the arrivals in the outdoor accommodations have increased by about $15 \%$ since 2010 [10]. The number of tourists in Italy was more than 131,000,000 in 2019, of which more than $10,000,000$ were arrivals in outdoor accommodations [9]. These numbers combined with a failed sustainability approach have a strong environmental and landscape impact. Within these structures, mobile homes represent the real actors of these contexts, being the most widespread typology, thus defining their landscape. The production of mobile homes operates independently of the context in which they are placed, creating environmental disconnections in which, at most, "façade operations" are activated which do not solve the environmental problem. Mobile homes are housing units on wheels for seasonal occupation produced on an industrial level and placed within the outdoor accommodation facilities. They have a usual dimension of $8 \times 4 \mathrm{~m}$, can accommodate up to six people, and consist of a kitchen-living room, bedrooms, and toilet and are usually connected to a veranda. They are designed to be easily transported usually by truck or by tow. The main characteristic of 
mobile home is that they do not need any permanent foundations, therefore they are easily removable. This last feature gives it a privileged position in the current European debate on the issue of land use. In fact, soil sealing is one of the main causes of soil degradation in the European Union, and to this end the European Commission is committed since 2011 to promoting a more sustainable use of land and soil, an objective made explicit with the "Roadmap to a Resource Efficient Europe" in which an increase in net land use equal to zero by 2050 is set as the goal. In these terms, the mobile home product is not permanently connected to the ground, therefore it does not consume soil and it gives rise to reversible settlements. This, connected to the fact that they are industrially produced and therefore with dry assembled materials and to the fact that they are flexible thanks to their transportability, represents a sustainable choice compared to ordinary buildings.

The use of sustainable materials is, today, still a distant topic in their application on mobile homes for tourism [11]. At a commercial level, the sustainability of materials is often less important than their availability, their adaptability to the production process, and their evolutionary readjustment. The application of alternative materials in mobile homes can be an opportunity to enhance this product, to create healthy architecture, and to react to contemporaneous problems such as climate change during its production and life cycle, as well as it representing a design opportunity. The use of sustainable building techniques with the use of structures built with ecological materials can drastically reduce the environmental impact of outdoor accommodations, so that they are non-invasive and in harmony with the natural scenario in which they are immersed.

Thus, the study started from two research questions: is it possible to build a sustainable mobile home for tourism following the existing assembly line of the industry? Can a sustainable mobile home for tourism be competitive within the existing tourism market?

The study will research some practical strategies to introduce sustainable construction in the mobile homes field, which has still not been adopted in this sector. Through the study of a mobile home prototype carried out within the AUDe (Architecture and Urban Design) laboratory of the Department of Civil Engineering and Architecture of the University of Pavia, currently put into production by the Crippacampeggio company (Carate Brianza, Italy), we want with this paper to promote the possibility of introducing alternative materials in an existing industrial chain to realize sustainable products like that of mobile homes.

\section{Productive Process}

The aim of the research is to analyze an existing industrial assembly line of mobile homes and insert into it alternative materials in order to enhance the product of the mobile home, transforming it into a sustainable industrial product. Thus, the earliest stage of the design process includes analysis of the assembly line, a study that allows, in the following stages, choosing the best eco-friendly materials (materials that are not harmful to the environment) that permit the maintenance of the same processing industrial techniques.

The analysis of the productive process was developed studying the productive line of one of the main Italian producers, a seller of Mobile Home Crippacampeggio, for which a prototype was designed that was an improvement in terms of naturality, recyclability, and of being recycled. The industry is located in different locations in northern Italy, one in Pavia where the prototype was developed, and it is the major producer in Italy of mobile homes, also exporting their products, mainly to Croatia where they have other factories. Its production system is based on a fast assembly line permitting them to produce at least 10 mobile homes per day. According to the assembly line, the production of each mobile home is based on phases during which each part of the mobile home is assembled. The assembly line moves from one point to another of the industry during its construction, permitting in a continuous way the work of the workers. Inside the industry, there is a rail path that permits them to push the mobile homes from one point to another according to the needed phase thanks to the presence of wheels under the mobile home. There are nine phases of production: 
- Chassis mounting: steel frame located on the base consisting of 2 or 4 wheels that supports the entire mobile home;

- Floor formation: includes different panel layers with structural function and insulation as well as the finishing layer;

- External walls elevation: includes insulation and the internal finishing layer;

- Partitions elevation: panels with their finishing layers;

- Ceiling formation: includes external and internal finishing layers and insulation;

- Realization of the electrical and water system;

- External finishing layer;

- Furniture insertion; and

- Finishes.

Each phase lasts $50 \mathrm{~min}$ and one mobile home is ready in $7.5 \mathrm{~h}$, with a total of 75 workers across all the phases. Regarding the production system and the realized product, which is prefabricated, it is obvious that all materials that are used must be dry assembled.

\section{Material and Methods}

\subsection{Current Materials}

For the analysis phase of the actual production, a basic model of mobile home produced by the industry was selected. The model selected is Evo and presents a simple structure; it is composed by a wooden frame while the rest of the components for the floor and wall system are made of panels that can be easily assembled.

The materials used to create the flooring and the walls are all wood, but mainly chipboard with a high percentage of formaldehyde. In particular, the chipboard used for the walls presents good percentages in terms of naturality and for being recyclable (respectively, $70 \%$ and $50 \%$ ) but a low percentage of being recycled, which is only $20 \%$. The finishing internal layer of the walls and ceiling is made of meranti, which belongs to the family of Shorea trees. About 50 species of Shorea are on the IUCN red list as they are endangered. Despite this, these trees are still cut illegally and used, and among the many wood companies, only few have obtained FSC certification, whose wood does not reach the European market. Meranti is configured as a sheet to which is applied a plastic film (kraft paper) to make wood waterproof. This means that the recycling process is impossible to apply due to the inability to decompose the material in its constituent parts. The same problem is faced in the furniture which is composed of chipboard, to which is applied a urea coating which is unsustainable, not natural, and unrecyclable.

The materials used for insulation comprise sandwich panels composed by steel sheet and polyurethane, which does not represent the best choice since it is impossible to decompose. Moreover, polyurethane is not natural and is unrecyclable, and even if the steel sheet could be recyclable, it could not be recycled because the remains would be contaminated by the glues and polyurethane.

The finishing layer of the floor is composed of linoleum which is not natural; it is realized in PVC, but is very cheap, easy to place and recyclable. The finishing external layer of the roof is made by a waterproof membrane made by PVC, thus $0 \%$ natural but $90 \%$ recyclable.

This first approach represents the starting point for the research, that permitted understanding the logic behind the choice of each material and their characteristics in terms of properties and natural, recycled, and recyclable percentage, useful for the second phase of the research.

The economic condition of a company has a very important influence on the sustainability financial statement; the aim of the research was indeed to act according to the model of a sustainable economy, a strategy that undoubtedly encounters limitations due to high costs and availability of materials. In fact, many of the materials, highly performing and sustainable, have a limited production and sometimes their companies do not export the products, thus not allowing their availability outside the country itself. Furthermore, 
many of these materials provide expert users and therefore have very high costs, which for a product such as that of the mobile home is inaccessible or at least not reproducible in a vision of future production. To improve the mobile home product in a real vision of production (and not in a utopian vision), different levels of sustainability have been taken into account: environmental (origin of raw materials), economic (economic accessibility and recycled and recyclable materials), and social (integration with landscape and health guarantee).

\subsection{Methodology and Legislation of Reference}

A mobile home model (EVO) was selected as a reference that could represent the best-selling product. This product was the starting point for research in terms of technical characteristics and environmental sustainability.

An itemized list of materials of all the components of the product was obtained from the company. From this, the incidence of each material was calculated based on its weight in relation to the total weight of the mobile home.

Systems, windows, and all accessory materials such as bathroom fixtures, monitors, and beds were not taken into consideration in this analysis because they were considered unessential for the purpose of the research.

Consulting the technical data sheets of the producers of the identified materials, three reference characteristics, natural, recycled, and recyclable, were analyzed.

Based on the weight of each material and in relation to its value in the triad of characteristics taken into consideration, an overall result for the EVO model was obtained by calculating the weighted average, resulting in the following: natural materials $38 \%$, recycled $10 \%$, and recyclable $82 \%$ (Figure 1 ).

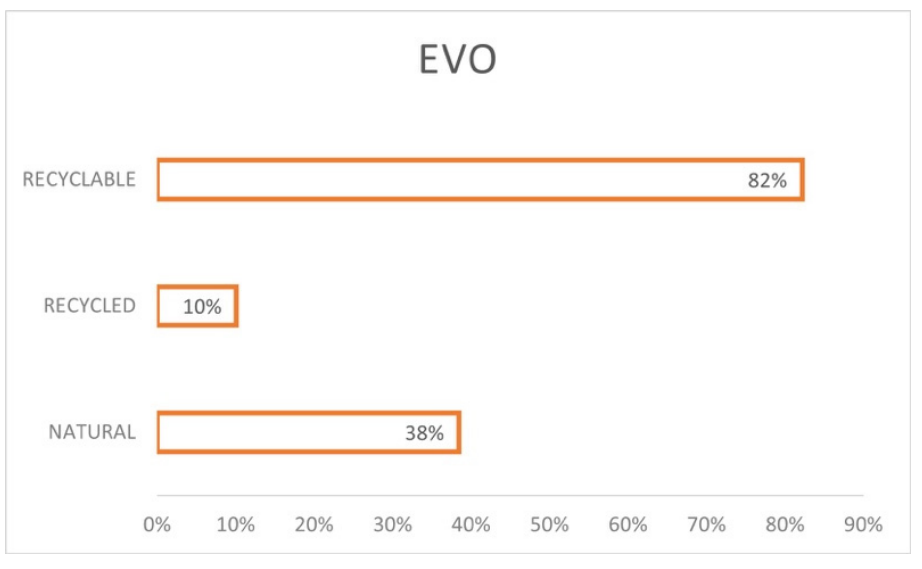

Figure 1. Percentage of the EVO model.

The mathematical formula of the weighted average was used for the calculation:

$$
\frac{x_{1} \cdot p_{1}+x_{2} \cdot p_{2}+\ldots+x_{n} \cdot p_{n}}{p_{1}+p_{2}+\ldots+p_{n}}
$$

Starting from these values, the research set the goal of improving each of them and reaching the threshold of the Italian legislation on CAM [12] for the recycled percentage.

The legislation imposes compliance with minimum environmental criteria and in particular the research focused on the construction sector, in which compliance becomes mandatory for the renovation and maintenance of public buildings in Italy, but it can still be used as a quality reference for any building or product that wants to increase its degree of sustainability.

The minimum thresholds in relation to the percentage of recycled and recyclable present within the product and materials are indicated in the annex dedicated to construction: $50 \%$ of the components must be disassembled, of which at least $15 \%$ that cannot 
be traced back to the supporting structure [13]. In the case of mobile homes, which are developed with dry technology, it is easier to achieve this goal for which a goal of $99 \%$ was set starting from a base of $82 \%$ (EVO).

Instead, $15 \%$ of the material by weight of the total must be composed of recycled raw material and among this percentage, $5 \%$ must not refer to the load-bearing structure [13]. It is evident that the reference model $(10 \%$ - percentage of recycled material in the EVO product) is below the expectations required by the legislation. The first goal of the research was to overcome this threshold.

The legislation also introduces clear objectives for each type of material used, in this case wood and insulating materials were taken into consideration.

The wood must come from sustainably/responsibly managed forests or it must be made from recycled wood or, even better, from both.

These characteristics are easily demonstrable through the PEFC and FSC certifications which have been decisive for the choice of wood materials, in the absence of such certifications, materials with certifications of equal importance were chosen [13].

\subsection{Process of Selection of the Materials}

Many factors influenced the choice of the different materials: ecology, industrial assembly line, and mechanical properties. To select the materials, a hierarchy was established in which the priorities linked to their characteristics that could best result a sustainable and eco-friendly final product and guide the choice of the materials were defined. These characteristics are represented by the intrinsic value of the material (natural, recycled, recyclable) [14]; from its availability; from the production costs; and from the cost of sale.

A compositional architectural choice was taken into consideration in order to promote the aesthetics of sustainability, capable of promoting an ecological product also on a technical level. The approach consists of the correspondence of the materials with the sustainability parameters that best adapt to the product and the current context: availability, naturalness (a product that is made from materials and ingredients found in nature, with little or no human intervention [15]), recyclability, and origin. Then, the technical characteristics of the materials in relation to the production system were taken into account: lightness, adaptability, fire resistance, and dry modularity. Faced with the selection process, the materials that were selected are:

- Wood (birch, conifer and bamboo)

- Natural linoleum

- Vegetable fiber

- Textiles

The following text is divided into the components that make up the mobile home, and each component comprises the description of the materials that have been chosen. Furthermore, for each material their certification is made explicit. Each certification is described below:

FSC certification [16] guarantees that the entire wood-paper supply chain certified for its standards derives from environmentally friendly, socially useful, and economically sustainable forest management.

CATAS CARB certification [17] is a certification regarding formaldehyde emission limits issued in wood-based products. The certification was born exclusively for the state of California; it then extended as a reference to many European companies.

PEFC certification [18] is a system of no-profit certification in which every single nation defines the management standards to follow to obtain the certification; it provides a guarantee that the certified wood and arboreal material contained in a product comes from sustainably managed forests.

\subsubsection{Flooring System}

The materials used by the industry for the flooring system are not very sustainable but are good in terms of mechanical characteristics; thus, they have been replaced maintaining 
their characteristics but improving their thermal performance by using a customized sandwich panel suitable for the assembly line.

The flooring system (Figure 2) is composed basically of four elements: two panels and the insulation panel composing the sandwich panel and the finishing layer. The panel located on the bottom part of the flooring is in close contact with the ground; for that reason, the resistance to humidity is relevant in the choice of the material. The first choice was a panel composed of hemp fibers joined by royal jelly, therefore $100 \%$ natural and $100 \%$ recyclable. This Canapalithos 1000 panel [14] (by CMF Greentech, Cavezzo, Italy) also had excellent water resistance properties. Unfortunately, it was not able to be adopted because it was temporarily removed from commercial production. Thus, a chipboard panel (Idroleb from Gruppo Saviola, Viadana, Italy [14]) that presents an excellent resistance to swelling $(24 \mathrm{~h}$, less than $8 \%)$ when in contact with water or humid contexts was selected. In addition, the choice led to this material because it is made up of $100 \%$ recycled raw materials which are FSC certified, and the panel with its components conforms to formaldehyde emissions meeting the CATAS CARB requirements.

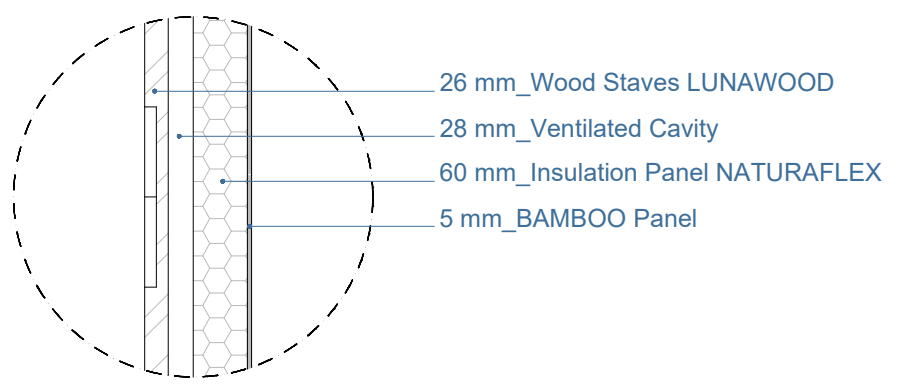

Figure 2. Details of the flooring system.

Above the chipboard panel is placed the insulation panel (Naturatherm by NaturaliaBau, Merano, Italy [14]), which is made of wood fiber which allows it to be easily workable and high density, the latter allowing it to resist crushing due to the weight on it (crushing $<10 \%, 200 \mathrm{kPa}$ ). The performance in terms of thermal insulation is excellent $(\lambda$ $0.045 \mathrm{w} / \mathrm{mk}$ ) and the panel is waterproof and breathable. Compared to the previous solution, it presents a greater thermal mass $\left(270 \mathrm{~kg} / \mathrm{m}^{3}\right)$ and a greater thermal mass capacity $(2100 \mathrm{~J} / \mathrm{kgK})$. This combination allows better insulation in the summer, the season when the product is used the most. Finally, the insulation components are made of $80 \%$ recycled materials, and the whole raw material is FSC certified.

The finishing layer is composed by a Linoleum roll (Marmoleum Cocoa by Forbo, Baar, Switzerland) $2.5 \mathrm{~mm}$ thick made up of natural raw materials (over 97\%), including recycled cocoa bean shells, a mix of linseed oil, wood flour, and a jute fiber net to reinforce the sheet. As an alternative to Marmoleum Cocoa, two other very ecologically and qualitatively valid materials were selected: Red Clay Hanji, a 100\% biodegradable vegetable paper linoleum, and Reclaimed Barrel Oak, recovered barrel wood planks. Both materials were discarded due to their difficult availability, being originally from South East Asia and North America.

Improving the flooring system by using sustainable materials made it possible to obtain a system composed of $100 \%$ natural materials, $92 \%$ recycled materials, and $100 \%$ recyclable materials.

\subsubsection{Perimetral System}

The entire structure of the mobile home is realized with a wood framework, of which the wood is FSC certified and supplied by Sveza company. Between the wooden pillars is placed the insulation, which is $60 \mathrm{~mm}$ thick. In its choice, plastic solutions were discarded, opting instead for a 100\% vegetable fiber panel (Naturaflex premium from NaturaliaBau, Merano, Italy). Its composition is $90 \%$ recycled fibers from jute bags, $8 \%$ reinforcement corn fibers, and $2 \%$ soda as flame retardant. The panel presents an excellent thermal performance $(\lambda 0.039 \mathrm{w} / \mathrm{mk})$ and it is appropriate during the summer thanks to its high 
thermal mass capacity $(2350 \mathrm{~J} / \mathrm{kgK})$, representing a great improvement from the prior solution which was in EPS.

The inner finishing layer is realized with bamboo panels $5 \mathrm{~mm}$ thick (Figure 3) or linoleum (Figure 4) $2 \mathrm{~mm}$ thick, all supported by a multilayer birch pane, which are the same materials chosen for the furniture and the partition walls and they will be analyzed further ahead.

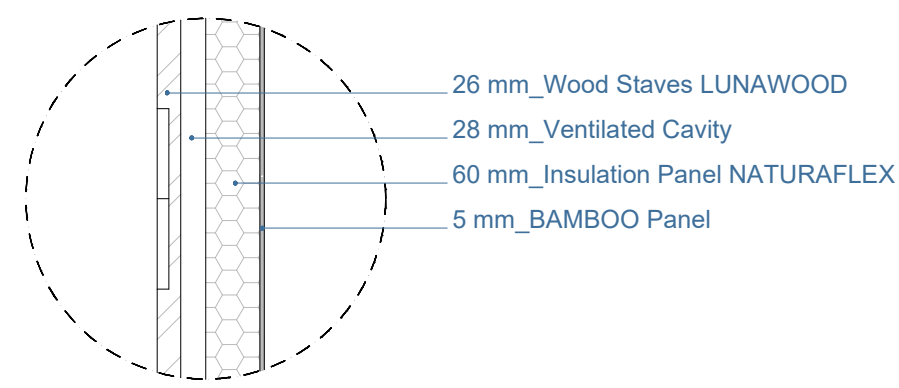

Figure 3. Detail of the perimetral system with bamboo as inner layer.

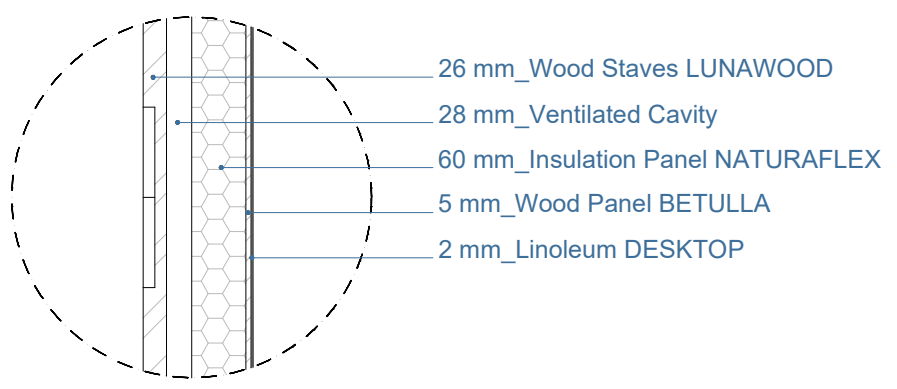

Figure 4. Detail of the perimetral system with natural linoleum as inner layer.

The façade was realized with coniferous wood staves (Jukola 3D by Lunawood, Lahti, Finland) which are PEFC certified. The wooden staves are heat-treated at high temperatures (between $190-192{ }^{\circ} \mathrm{C}$ ) through heat and steam processes, thus making the wood resistant to unfavorable external climatic conditions without the addition of further treatments based on chemical substances such as solvents or paints. Each stave is $30 \mathrm{~mm}$ thick with rabbet joints making the application easy. The staves are screwed to wooden batons attached to the underlying wooden structure, leaving an adequate air chamber $30 \mathrm{~mm}$ thick to ensure ventilation of the façade. The pattern that characterizes the façade has been realized through a numerical control machine giving a 3D surface.

The perimetral system is $100 \%$ natural, $8 \%$ recyclable, and $100 \%$ recycled.

\subsubsection{Roof System}

To make the roof system perfectly adapted to the assembly line and due to structural and waterproofing necessities, it was not possible to make it completely customized. Nevertheless, for most of the materials, the percentages in terms of naturality, recyclability, and recycled nature of the materials were greatly improved.

The roof (Figure 5) is composed by an inner finishing layer made of recycled textile materials-Acoustic Textile Felt-(developed by Really, Copenhagen, Denmark) hooked to multilayer birch panel $6 \mathrm{~mm}$ thick. The textile panels are $10 \mathrm{~mm}$ thick and $70 \%$ made of recycled textiles coming from the world of fashion. The panels can be in cotton or wool and are obtained through different pressing processes making them suitable for acoustic insulation (NCR 0.45). The load-bearing and insulating part of the structure is made up of sandwich panels $50 \mathrm{~mm}$ thick (Isodeck by Isopan, Verona, Italy). The panel is made of two metal sheets that protect the insulation panel from water and humidity; the inner layer is 
made of rockwool which is $47 \%$ composed of recycled materials and $100 \%$ recyclable. The whole production process of the insulation panel is LEED certified.

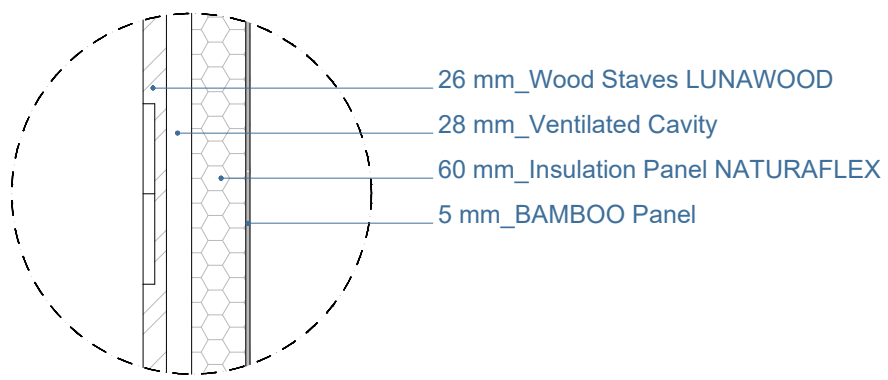

Figure 5. Detail of the roof system.

A PVC membrane-Alkorbright (by Renolit, Worms, Germany)—supplied in rolls and heat-sealed to the underlying sandwich panel during the laying is applied to the outer layer of the roof to make the mobile home waterproof. Furthermore, thanks to the high solar reflectance of the material, which is on average $90.5 \%$, it protects the mobile home from solar radiation during summer periods.

The roof system is $65 \%$ made of natural materials, $33 \%$ made of recyclable materials, and $99 \%$ coming from recycled materials.

\subsubsection{Furniture and Partition Walls}

For the furniture and partition walls (Figure 6) realization, the usage of panels (usually chipboard) with a high percentage of melamine and plastic contents with high emissions of formaldehyde is common. Thus, the challenge was to use natural materials as much as possible avoiding artificial and polluting contents. For the construction of the internal walls and the furniture, two materials were first selected. One was Really's Solid Textile Board, a rigid panel made of $70 \%$ recycled cotton from the fashion supply chain. This $8 \mathrm{~mm}$ thick rigid panel is perfectly suitable for the construction of furniture; unfortunately, the price was not comparable with the solution adopted later.

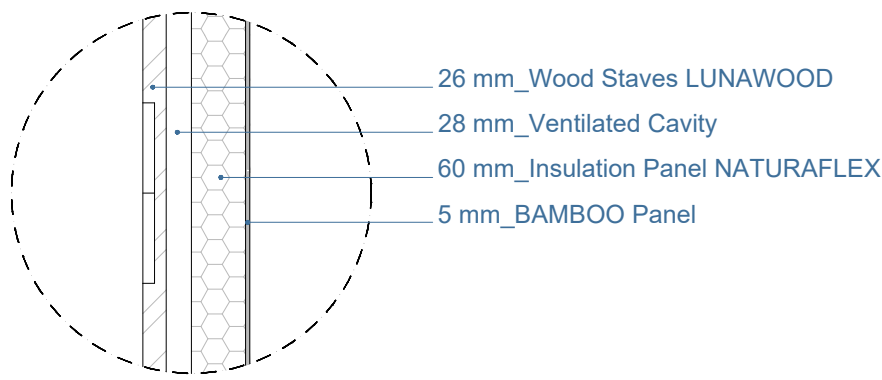

Figure 6. Detail of the partition wall.

Another option was Organoid, a laminate made of $100 \%$ natural and $100 \%$ recyclable herbaceous essences. However, the very high price of this material was the decisive factor in opting for two other solutions.

The selection led to a multilayered birch panel being chosen for the structure (supplied by Sveza, Saint Petersburg, Russia). The finishing of the panel has a good performance, allowing it to be exposed without adding paints or solvents in some part, while it has been covered in others. Two different types of material were chosen for the internal lining: bamboo panels (by Moso, Zwaag, The Netherlands [14]) $5 \mathrm{~mm}$ thick and FSC certified, and natural linoleum $2 \mathrm{~mm}$ thick (Desktop series by Forbo, Baar, Switzerland). The bamboo panels were left natural; thus, they are $100 \%$ recyclable, representing a great alternative to tropical woods increasingly scarcely available and sustainable. Furthermore, bamboo 
panels are $\mathrm{CO}_{2}$ neutral and $\mathrm{HCHO} \mathrm{E} 1$ certified. The linoleum used is completely analogous to the one used for the flooring with the only difference being that the product was specifically realized for the furniture upholstery. The percentage of recycled materials used for furniture and partition walls if compared with EVO was the only one that decreased. This is because more importance was given to the absence of formaldeyde (present in chipboards) than to choosing a natural material as birch is.

\section{Results}

\subsection{Natural, Recycled, and Recyclable Mobile Home}

In a view of ecological and healthy design, the objective of the research was to improve the industrial product of the mobile home. Three factors referred to materials mainly influenced the research: naturality, to be recycled, and recyclability of the materials. The challenge was to calculate the percentage of the three factors of a standard mobile home and compare it to the new sustainable product in order to understand if it is possible today to introduce innovative and eco-friendly materials in the current assembly line. The percentages were calculated on the volume of each material, which allowed us to also keep in consideration the light materials. First, we calculated the percentage of naturality, been recycled, and recyclability for each component of the mobile home: flooring system, perimetral system, and roof system. The result was that compared to the current mobile home, with the new materials, it is possible to obtain $100 \%$ naturality for the flooring and perimetral system and that all the components are $100 \%$ recyclable, excluding the roof system, which is $99 \%$ recyclable. This means that for most of the components, the percentage doubled. At the end, we compared the percentages of the three factors on the mobile homes in total. The result was that the mobile home actually in production is $38 \%$ natural, $10 \%$ recycled, and $82 \%$ recyclable, while the same mobile home but with eco-friendly materials is $92 \%$ natural, $35 \%$ recycled, and $100 \%$ recyclable (Figures 7 and 8 ). This means that the sustainable mobile home is a healthy product thanks to its naturality and is built with a future perspective of the closed circulation of its components.

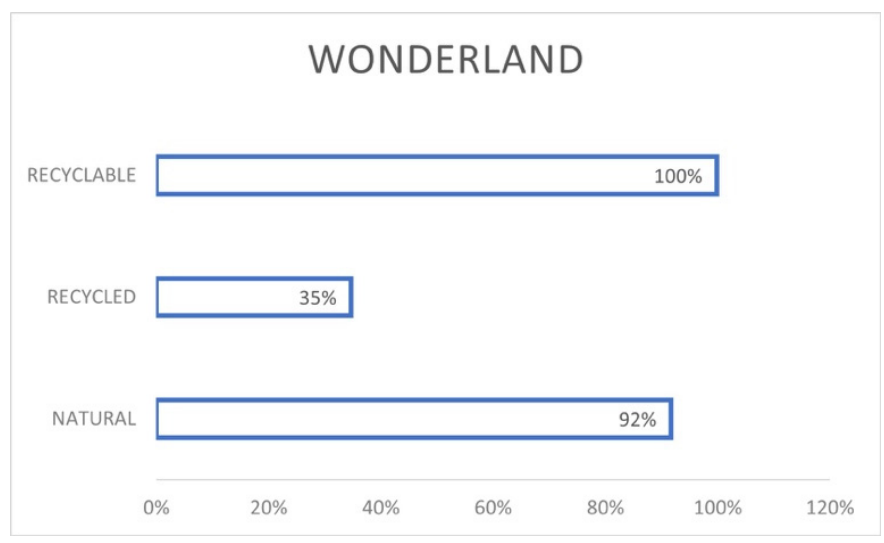

Figure 7. Percentages of Wonderland. 


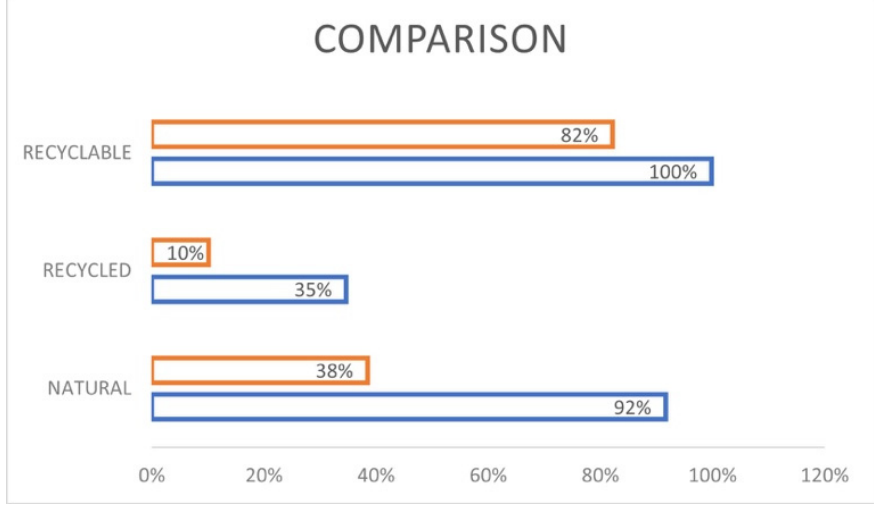

Figure 8. Comparison of the EVO model and Wonderland.

\subsection{Discussion}

With tourism being a sort of representation of the contemporary society, there is all the more reason for the sector to be expected to demonstrate sensitivity to issues of ecology and sustainability, in which it can trace the path to conscientious planning. The research outcomes demonstrate the possibility of implementing an existing production system with unexpected results. The fact that the research has constantly confronted itself with an existing reality and has not set itself the goal of overcoming it opens a window for the construction world and in particular for the world of outdoor tourism in which the mobile home product is involved. The result obtained shows that the architectural project can work synergistically and in harmony with the more technical aspect in a sustainable vision without falling into a mere "façade operation". This means that the use of sustainable materials is not a topic so far from the product of mobile homes. On the contrary, the application of innovative materials can give added value to a product which by its very nature is in a privileged position being mobile and therefore removable architecture.

Designing Wonderland, a series of construction systems and materials were evaluated to provide a low environmental impact, constructive simplicity, low costs, and all the characteristics necessary for a replicability of the prototype. The prototype makes use of new sustainable materials that allow a lightweight and easily achievable construction within the assembly line. The natural materials used are intended to promote the integration of the mobile home product with the surrounding environment and an attempt was made to obtain a sustainable structure with a reversible environmental impact.

Wonderland embodies the principles and objectives that the Laboratory of the University of Pavia, AUDe, and the company Crippacampeggio (Carate Brianza, Italy) set themselves: wellbeing, simplicity, innovation, and sustainability. Sustainability and ecology were one of the main concerns during the development of the project which led to the development of a highly natural, recycled, and recyclable mobile home prototype for outdoor tourism. The intention was to explore the design of the minimum space in an innovative way and to minimize the impact on the environment as much as possible. The prototype of a reversible and recyclable mobile home actually built within an industrialized sector can represent a turning point and the key to a new type of design and construction of this type of product that is more sensitive in ecological terms. This prototype is intended as a demonstration that with a more conscious design, it is possible to innovate a product that is currently highly demanded in the 'leisure' sector and that is at the same time respectful of the environment.

\section{Conclusions}

Until now, the mobile home sector for outdoor tourism has neglected sustainable architectural and technical choices and has instead only considered the factor of easy removal as a sufficient feature to make it of low environmental impact; thus in the face of new needs, sustainability is no longer ignorable. 
The aim of the research was to transform a standard mobile home into an eco-friendly product compliant with new demands in the building field in terms of sustainability without changing the assembly line of the industry. There were relevant limitations during the research process such as the costs that should not exceed those which the company currently incurs for the construction of a standard mobile home and the construction system that forced the choice of prefab materials that are dry assembly. Nevertheless, a strategy for the choice of the materials of the mobile home sector (natural, recycled, and recyclable) was developed that can be applied in a broad way to the entire building sector. The strategy was developed in order to obtain materials for long-term usage in construction representing a good practice of circular economy (Figures 9-12).

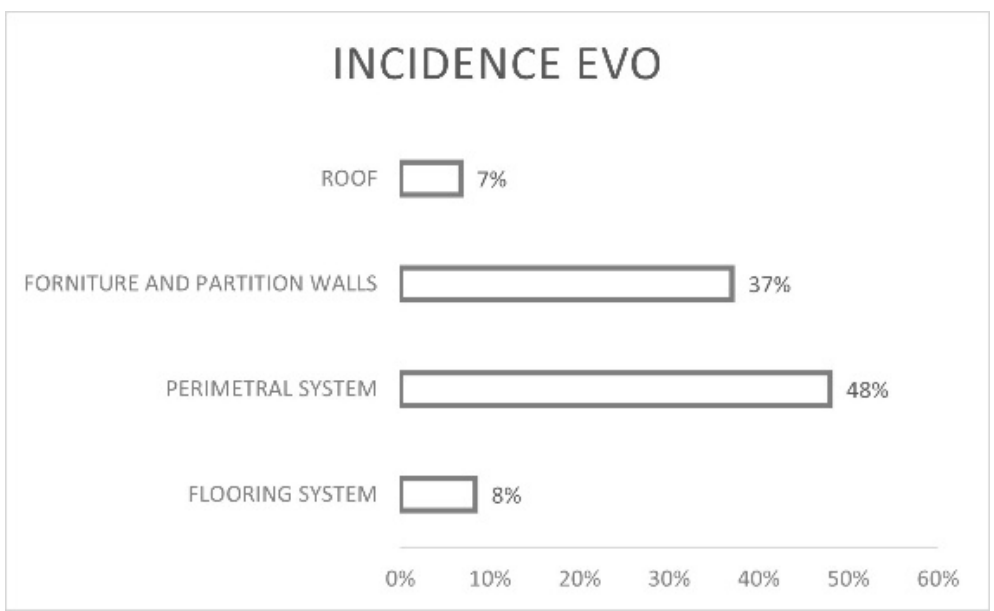

Figure 9. Incidence of components in EVO model.

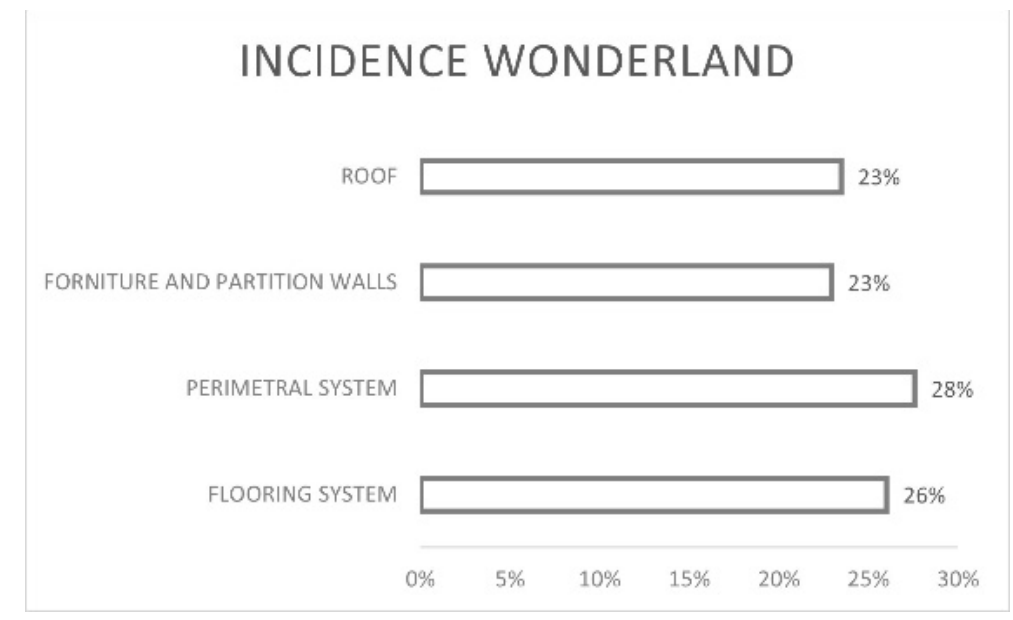

Figure 10. Incidence of components in Wonderland. 


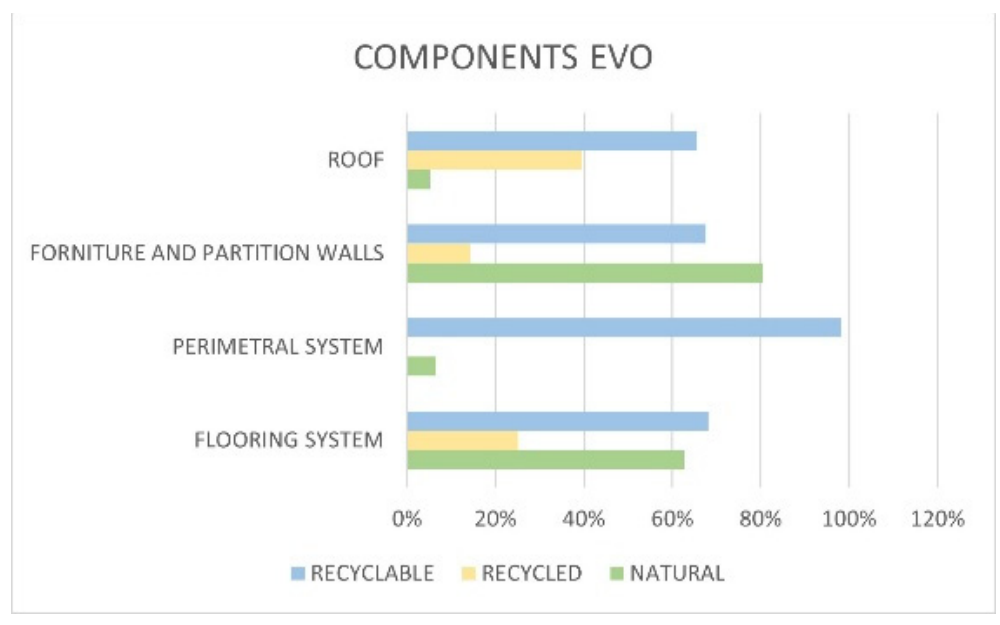

Figure 11. Percentage for each component in the EVO model.

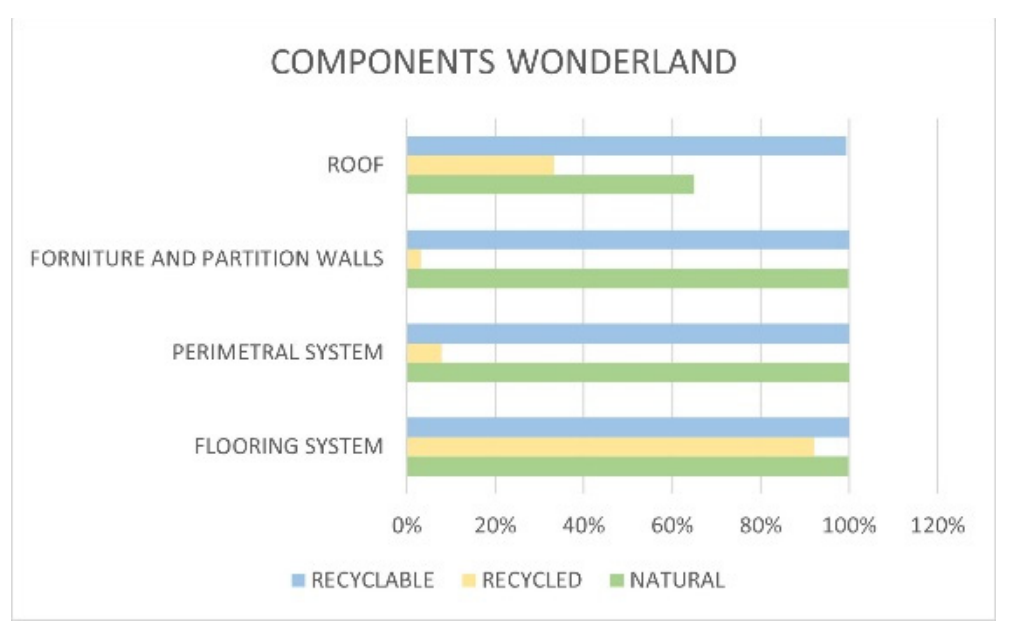

Figure 12. Percentage for each component in Wonderland.

The research highlights the possibility of a product being sustainable, environmentally friendly, and healthy for humans that, more than others, needs to be integrated with nature as it is placed in open air accommodations which are usually of particular beauty in terms of landscape.

The study demonstrates that introducing innovative materials in terms of sustainability is an opportunity that is not so far from our reality.

The output of the research was the production through the company Crippacampeggio (Carate Brianza, Italy) of a prototype (Figures 13 and 14) of a 92\% natural, 35\% recycled, and $100 \%$ recyclable mobile home, inserting itself within the production process currently in use by the company without interfering with the current assembly line. Possible developments of the research that is being carried out in the AUDe laboratory have as objectives not only the mobile home product, but the entire process being certified, from production to its use, thus paying attention to every single phase. An example to consider is the certification of the final product through a protocol known worldwide such as LEED. Thus, attention is therefore placed on materials and in particular on their origin, disposal, and recyclability. Furthermore, in the industrial point of view, today, products and wastes are produced simultaneously, where instead it would be necessary to direct the industry sector towards ecology, structuring it to measure the environmental impacts. It is necessary to produce light structures by using recycled/recyclable materials or components, thus improving the environmental performance and reducing the costs in a cyclic view and reducing embodied energy as well as deleting waste [19]. Focusing on reducing embodied 
energy, which means consumed energy during extraction, processing of raw materials, transportation, and construction and demolition processes, allows us to reduce the impact on the environment and to design long-lived constructions [20]. It is not only the attention on embodied energy that allows us to plan consciously, but also the search for a NZEB product can have an impactful effect on the environment and on the performance of the building. The use of this type of approach on a product such as that of mobile homes allows a significant reduction in costs due to the maintenance, heating, and cooling of the housing units, especially during the summer, when they are most used.
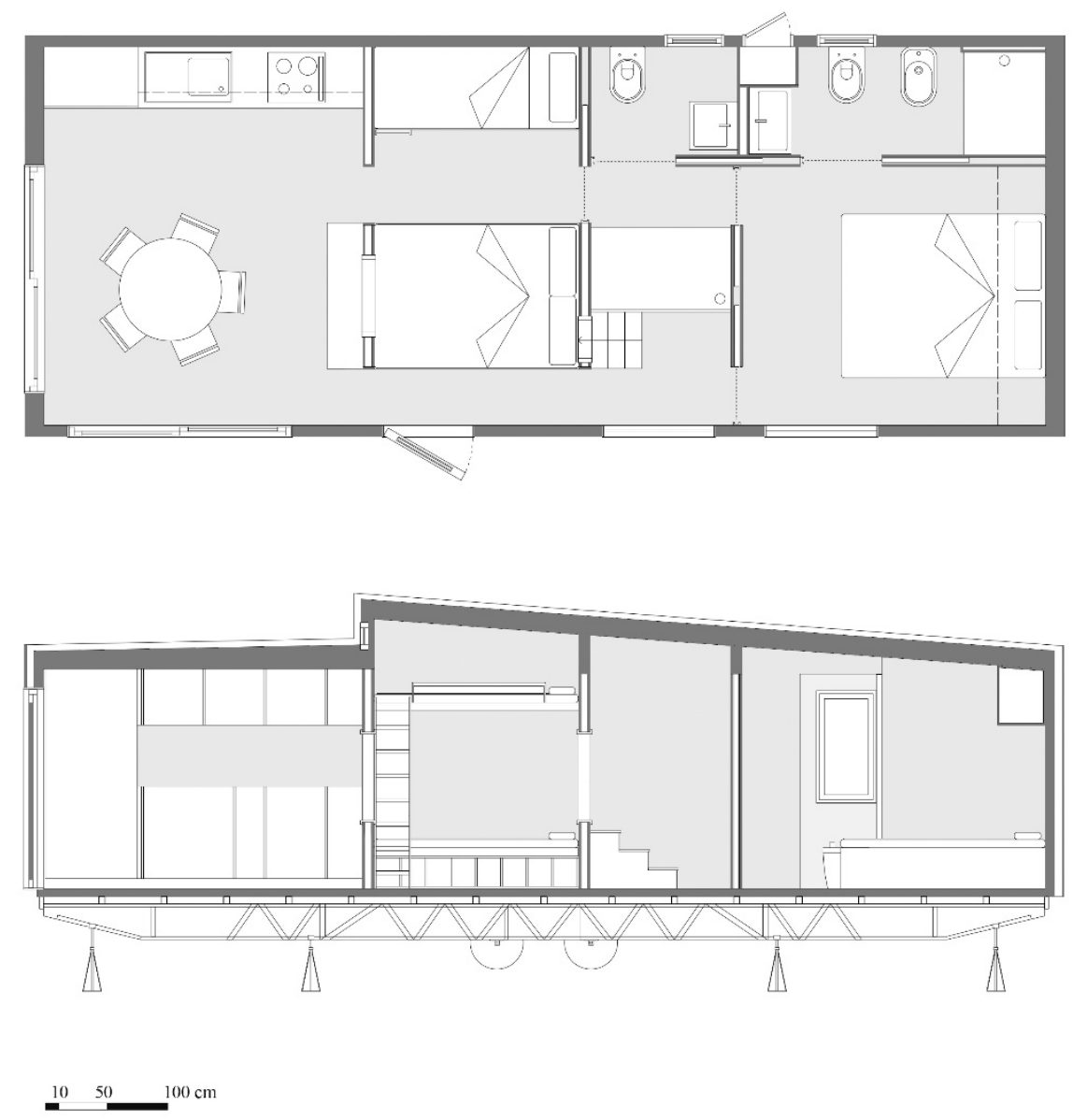

Figure 13. Plan and section of the prototype. 


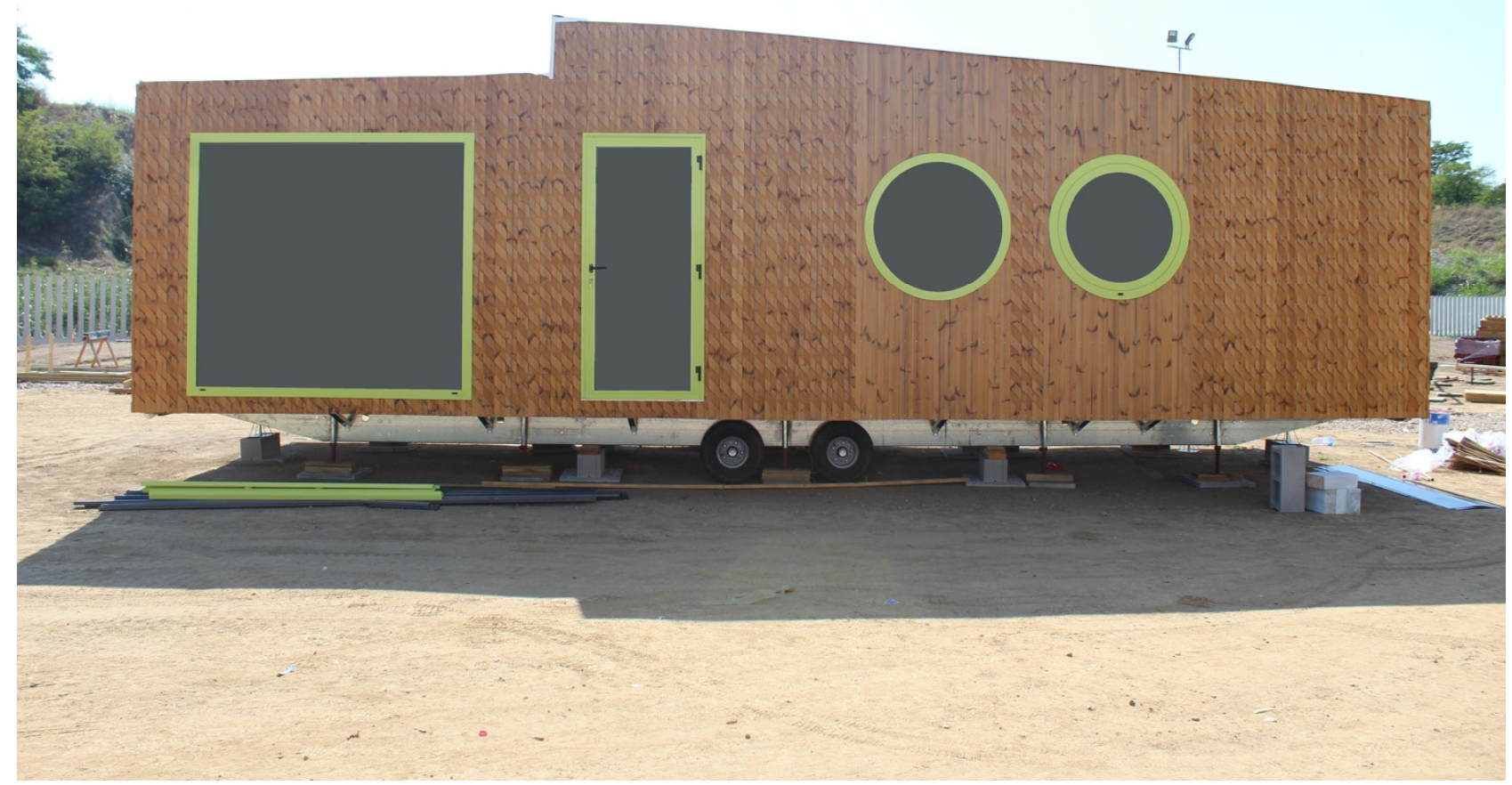

Figure 14. Picture of the prototype in phase of construction.

Author Contributions: Conceptualization and supervision, C.B. and L.T.; funding acquisition and methodology, C.B.; research on sustainable materials and technical details, L.T.; investigation and original draft preparation, G.N.T.; review and editing, G.N.T. and S.N.; industrial process and data curation, S.N. All authors discussed the results and commented on the manuscript. All authors provided critical feedback and helped shape the research and the manuscript. All authors have read and agreed to the published version of the manuscript.

Funding: This research was funded by Crippacampeggio.srl.

Institutional Review Board Statement: Not applicable.

Informed Consent Statement: Not applicable.

Data Availability Statement: Not applicable.

Conflicts of Interest: We, Carlo Berizzi, Salvatore Nirta, Gaia Terlicher, and Luca Trabattoni, declare that we have no economic or personal relationships that can inappropriately influence the scientific input presented. We declare that we authorize the publication of the scientific contribution presented, as well as the processing of personal data entered for the exclusive purposes of the journal.

\section{References}

1. Kappenthuler, S.; Seeger, S. From resources to research-A framework for identification and prioritization of materials research for sustainable construction. Mater. Today Sustain. 2019, 7-8, 1-14. [CrossRef]

2. Karim, M.R.; Zain, M.F.; Jamil, M.; Lai, F.C.; Islam, M.N. Use of Wastes in Construction Industries as an Energy Saving Approach. Energy Procedia 2011, 12, 915-917. [CrossRef]

3. Charytonowickz, J.; Skowronski, M. Reuse of building materials. Procedia Manuf. 2015, 3, 1633-1637. [CrossRef]

4. Environment Programme. Changes in Building and Construction Have Great Potential to Slow Global Warming. 2020. Available online: www.unenvironment.org/news-and-stories/story/changes-building-and-construction-have-great-potential-slowglobal-warming (accessed on 12 March 2020). 
5. Global Alliance for Buildings and Construction, International Energy Agency and the United Nations Environment Programme. 2019 Global Status Report for Buildings and Construction. Towards a Zero-Emissions, Efficient and Resilient Buildings and Construction Sector; Job No: (DTI/2265/PA); United Nations Environment Programme: Nairobi, Kenya, 2019.

6. Ng, W.Y.; Chau, C.K. New life of the building materials-recycle, reuse and recovery. Energy Procedia 2015, 75, $2884-2891$. [CrossRef]

7. Bruscino, A. Lo Sviluppo Ecosostenibile; Libreriauniversitaria.it Editore: Padua, Italy, 2008.

8. Bribiàn, I.Z.; Capilla, A.V.; Usòn, A.A. Life Cycle assessment of building materials: Comparative analysis of energy and environmental impacts and evaluation of the eco-efficiency improvement potential. Build. Environ. 2011, 46, 1133-1140. [CrossRef]

9. Augè, M. Rovine e Macerie; Il senso del tempo; Bollati Boringhieri: Turin, Italy, 2004.

10. ISTAT. (n.d.). Informazioni Sulla Rilevazione: Capacità Degli Esercizi Ricettivi. Available online: https://www.istat.it/it/ archivio/210783 (accessed on 4 August 2020).

11. Berizzi, C.; Trabattoni, L. Mobile Home per il Turismo All'aria Aperta, Storia Evolutiva; Vicolo del Pavone Editore: Tortona, Italy, 2019.

12. Decreto 11 Gennaio. 2017. Criteri Ambientali Minimi, in G.U, anno n ${ }^{\circ} 158$, n. 259. Available online: https: / /www.minambiente. it/sites /default/files/archivio/allegati/GPP/GU_259_dm_CAMedilizia.pdf (accessed on 12 June 2021).

13. D.M. 11 ottobre. 2017. “Criteri Ambientali Minimi per l'affidamento di servizi di progettazione e lavori per la nuova costruzione, ristrutturazione e manutenzione di edifici pubblici", in G.U.,anno 158, n. 259 (allegato 2). pp. 37-38. Available online: https:/ / www.minambiente.it/sites/default/files/archivio/allegati/GPP/allegato_tec_CAMedilizia.pdf (accessed on 12 June 2021).

14. Legambiente. Rapporto dell'Osservatorio Recycle. 100 Materiali per una Nuova Edilizia. 2016. Available online: https://www. legambiente.it/sites/default/files/docs/cento_materiali_rapporto_osservatorio_recycle.pdf (accessed on 1 June 2021).

15. Burden, E. Illustrated Dictionary of Architecture; Mc-Graw Hill Education: New York, NY, USA, 2012.

16. FSC. (n.d.). I Marchi FSC. Available online: www.it.fsc.org/it-it/certificazioni/i-marchi-fsc (accessed on 20 May 2020).

17. CATAS Testing Certification Research. (n.d.). Catas Quality Award. Available online: https://catas.com/it-IT/page/entecertificazione-cqa (accessed on 20 May 2020).

18. PEFC. (n.d.). Uso dei Marchi PEFC. Available online: www.pefc.it (accessed on 20 May 2020).

19. Morini, A.A.; Ribeiro, M.J.; Hotza, D. Early-stage materials selection based on embodied energy and carbon footprint. Mater. Des. 2019, 178, 1-13. [CrossRef]

20. $\mathrm{Hu}, \mathrm{M}$.; Milner, D. Visualizing the research of the embodied energy and environmental impact research in the building and construction field: A bibliometric analysis. Dev. Build Environ. 2020, 3, 1-14. [CrossRef] 